\title{
INVESTIGACIÓN
}

Recibido: 05/11/2019 --- Aceptado: 18/12/2019 --- Publicado: 15/06/2020

\section{INSTAGRAM COMO HERRAMIENTA DE APRENDIZAJE MUSICAL EN EDUCACIÓN SECUNDARIA Y BACHILLERATO}

\section{Instagram as a musical learning tool in secondary education and high school}

José Salvador Blasco Magraner1. Universidad de Valencia. España. j.salvador.blasco@uv.es

Rubén López Ramos. Universidad de Valencia. España. $\underline{\text { Ioraru@alumni.uv.es }}$

\section{RESUMEN}

El uso de metodologías renovadoras que incluyan elementos atractivos para el alumnado de la ESO y Bachillerato está relacionado en muchos casos por la utilización de recursos TIC, cuyas aplicaciones en el aula de secundaria y de bachillerato se realizan mediante plataformas creadas con fines didácticos con un uso restringido al ámbito académico. No obstante, estas aplicaciones no figuran entre las que más utilizan los jóvenes de nuestro país por voluntad propia. En este sentido, en el presente artículo se ha implementado una intervención didáctica en dos grupos de $4^{\mathrm{o}}$ curso de ESO y primer curso de bachillerato de un instituto público de la zona metropolitana de la ciudad de Valencia, en las asignaturas de música y de análisis musical respectivamente, que se sirve de la red social Instagram como herramienta de aprendizaje de los contenidos musicales que se están impartiendo en el libro de texto de forma tradicional. La aplicación de Instagram con el fin de crear memes de los contenidos que se están impartiendo en las asignaturas de música en estos niveles académicos mejoran los resultados de aprendizaje del alumnado de forma muy positiva. Asimismo, este tipo de actividades resultan muy motivadoras para el alumnado frente a las metodologías convencionales.

PALABRAS CLAVE: Instagram - educación musical - educación secundaria bachillerato - nuevas metodologías - TIC - memes.

\footnotetext{
${ }^{1}$ José Salvador Blasco Magraner: Doctor en Sociología y Ciencias Humanas. Profesor Ayudante Doctor de la Universidad de Valencia en el Departamento de Didáctica de la Expresión Musical, Plástica y Corporal.
} 


\begin{abstract}
The use of renovating methodologies that include attractive elements for ESO and high-school students is related in many cases to the use of ICT resources, whose applications in the secondary and high-school classroom are carried out through platforms created for educational purposes with a use restricted to the academic field. However, these applications are not among the most used by young people in our country of their own free will. In this sense, in this article a didactic intervention has been implemented in two groups of the 4th year of ESO and the first year of high school in a public institute in the metropolitan area of Valencia City, in the subjects of music and musical analysis respectively, which uses the social network Instagram as a learning tool for the musical content that is being taught in the textbook in a traditional way. The application of Instagram in order to create memes of the contents that are being taught in music subjects at these academic levels improve the learning results of students in a very positive way. Also, these types of activities are very motivating for students as compared to conventional methodologies.
\end{abstract}

KEYWORDS: Instagram - music education - secondary education - baccalaureate classroom - new methodologies - ICT - memes.

\title{
INSTAGRAM COMO FERRAMENTA DE APRENDIZADO MUSICAL NO ENSINO FUNDAMENTAL E MÉDIO
}

\section{RESUMO}

O uso de metodologias inovadoras que incluem elementos atrativos para os alunos do ensino médio está relacionado em muitos casos à utilização de recursos TIC, cujas aplicações na sala de aula do ensino médio se realizam mediante plataformas criadas com fins didáticos com um uso restringido ao ambiente acadêmico. Não obstante, estas aplicações não estão listadas entre as que mais são utilizadas pelos jovens do nosso país por vontade própria. Nesse sentido, no presente artigo tem sido implementado uma intervenção didática em dois grupos de $4^{\circ}$ ano do ensino fundamental e primeiro ano do ensino médio de um instituto público da zona metropolitana da cidade de Valência, nas matérias de música e de análise musical respetivamente, onde é usada a rede social Instagram como ferramenta de aprendizado dos conteúdos musicais que estão sendo ensinados no livro de texto de forma tradicional. A aplicação de Instagram é feita com a finalidade de criar memes dos conteúdos que se estão sendo ensinados nas matérias de música nestes níveis acadêmicos o que melhora os resultados de aprendizado dos alunos de forma muito positiva. Igualmente, este tipo de atividades resultam muito motivadoras para os alunos em comparação às metodologias convencionais.

PALAVRAS CHAVE: Instagram - educação musical - ensino fundamental - ensino medio - novas metodologias- TIC - memes. 


\section{Cómo citar el artículo:}

Blasco Magraner, J. S. y López Ramos, R. (2020). Instagram como herramienta de aprendizaje musical en educación secundaria y bachillerato. [Instagram as a musical learning tool in secondary education and high school].Vivat Academia. Revista de Comunicación, (151), 25-45. doi: http:/ / doi.org/10.15178/va.2020.151.25-45

Recuperado de http://www.vivatacademia.net/index.php/vivat/article/view/1207

\section{INTRODUCCIÓN}

El uso generalizado de las nuevas tecnologías ha revolucionado muchos aspectos de la vida cotidiana. Según datos de la compañía International Telecommunication Union (ITU) “en el año 2005 había el mundo 1.024 millones de personas que usaban Internet, mientras que en 2016 la cifra asciende hasta los 3.488 millones de ciber habitantes" (Alonso, 2017, p. 41). En este contexto, la mediatización de la información supone hoy día un espectro totalmente distinto y reconfigurado (Campos, 2008). Uno de los dispositivos que más han contribuido a hacer posible este hecho son los móviles o smartphones, mediante los cuales se puede acceder a internet y "se pueden usar como ordenador de bolsillo" (González et al., 2015, p. 132).

Los datos estadísticos del Informe Ditrendia Mobile en España y en el mundo (2018) son sumamente reveladores del uso masivo del dispositivo móvil en la actualidad. Así, por ejemplo, en España el 97\% de los españoles se sirve del móvil como primer dispositivo de acceso a internet, mientras que el $49 \%$ de los jóvenes con edades comprendidas entre los 18 y los 24 años dedican más de 4 horas diarias a este dispositivo. Cabe mencionar que las actividades más realizadas desde el móvil son las que atañen a esta implementación didáctica: la mensajería instantánea y las redes sociales (74\%). Asimismo, las Apps ocupan más del 80\% del tiempo que dedicamos al uso del móvil, siendo las aplicaciones de redes sociales gratuitas las más utilizadas, seguidas de las de mensajería instantánea (Ditrendia, digital marketing trends, 2018).

Un factor muy relevante a tener en cuenta es el intenso uso que los adolescentes y jóvenes hacen de las redes sociales en general (Sherman, Payton, Hernández, Greenfield y Dapretto, 2016). Por ejemplo, el 38\% de los usuarios de Instagram tienen una edad comprendida entre los 13 y 24 años, mientras que el 33\% se halla entre los 25 y 34 años (Statista, 2019). Un estudio realizado en Valladolid afirma que el 89,3\% de 2.412 adolescentes escolarizados entre los 13-18 años de edad usa internet para acceder a las redes sociales (González et al., 2015).

La interacción social, el almacenamiento, la autoexpresión, la evasión, y el cotilleo son algunos de los principales motivos por los que el alumnado comprendido en este rango de edad hacen un uso tan elevado de estas Apps (Kamel, Boulos, Giustini y Wheeler, 2016, p. 7). En muchos casos los jóvenes no son conscientes de los posibles riesgos que conlleva el uso excesivo de las Apps (González et al., 2015). Así, por ejemplo, trastornos como la ansiedad o la depresión en el periodo de la adolescencia 
pueden ser provocados por un mal hábito en la utilización de este tipo de redes sociales (Oberst, Wegmann, Stodt, Brand y Chamarro, 2017). Además problemas como el ciberbullying, grooming, sexting o sextorsion son relativamente comunes entre los adolescentes. Asimismo, existe la "identidad digital", definida como "la imagen que los adolescentes transmiten en las redes sociales. Es una combinación de aquello que son y lo que les gustaría llegar a ser" (Gabarda, Orellana y Pérez, 2017, p. 252). Alonso (2017) asevera que "debido a la situación de especial vulnerabilidad en la que los y las adolescentes se encuentran, pueden enfrentarse a consecuencias absolutamente nocivas para su correcto desarrollo psicológico, afectivo y social" (p. 94).

Existen también redes sociales creadas y diseñadas estrictamente para cumplir una función pedagógica como Leoteca, Interuniversidades, Cibercorresponsales, Internet en el aula, Clipit, Brainly, Docsity, Edmodo, Eduskopia, Comunidad Todoele, Otra Educación y RedAlumnos, Schoology (Educación 3.0, 2018). Otro ejemplo de red social aplicada a la docencia sería el proyecto Aula-Twitter, llevado a cabo por profesores pertenecientes al grupo de trabajo "Hagamos Música"; pensado y realizado para alumnos de $3^{\circ}$ y $4^{\circ}$ de la ESO. Este proyecto aprovecha el potencial comunicativo de la App "Twitter" (Kwak, Lee, Park y Moon, 2010) para trabajar contenidos teóricos de la asignatura de música.

El uso de las TIC en las aulas puede ser una alternativa atractiva para los alumnos frente a metodologías más tradicionales (Gabarda, Orellana y Pérez, 2017). No obstante, la implementación en el aula de las redes sociales supone un esfuerzo extra para el docente. Cabe decir que el fenómeno social relacionado con la interacción en internet mediante las redes sociales o blogs, se denomina Web 2.0. Se trata de un término acuñado en 2003 para marcar la diferencia de uso de internet entre el antes y el después de las redes sociales y espacios similares (Gabarda, Orellana y Pérez, 2017).

El hecho de que este tipo de herramientas sean tan prácticas a la hora de aplicarlas en una clase viene de su propia idea original; y es que posiblemente, el éxito de las redes sociales actuales radica en la participación de los usuarios como protagonistas de la acción (Moreno, 2018). Las redes sociales poseen el poder de captar y mantener la atención de sus usuarios; de hecho, están continuamente en proceso de desarrollo y actualización con el objetivo de no parecer monótonas. Este hecho es de suma importancia, ya que por medio de la innovación didáctica las redes sociales pueden convertirse en herramientas que fomentan la participación individual y colectiva del alumnado, al tiempo que favorecen el trabajo colaborativo en el proceso de aprendizaje (Educaweb, 2018).

Dentro de este ámbito de actuación es necesario ser conscientes de la realidad que rodea al alumnado para poder diseñar propuestas que garanticen el aprendizaje de los jóvenes (Blanco, 2017). En este sentido se han realizado varios estudios utilizando la red social Instagram con fines pedagógicos. Las investigaciones han sido realizadas con estudiantes de distintos niveles, universitarios y adultos, y en especialidades diferentes: arquitectura, veterinaria y poesía (Jurado, Woelfert, 
Giovagnola, Faisal y Peralta, 2018; Blanco y López, 2017; Moreno, 2018). En las tres investigaciones se hace hincapié en la validez de Instagram como herramienta para construir el aprendizaje mediante el trabajo colaborativo y grupal: "Concluimos que la experiencia fue positiva para todos y que conociendo mejor la herramienta podremos contribuir a anclar y construir el conocimiento disciplinar mediante el uso de una red social como Instagram" (Jurado, et al., 2018, p. 66). Por su parte, Blanco y López (2017) concluyen que "las redes sociales pueden convertirse en espacios virtuales de aprendizaje con múltiples posibilidades para el aprendizaje de contenidos puramente teóricos, así como de contenidos de carácter social y cívico" (p. 9).

Actualmente el formato de imagen más utilizado en Instagram es el llamado "meme". Diversos autores coinciden en apuntar el primer uso de la palabra meme en 1976 en el libro 'The Selfish Gene' del biólogo Richard Dawkins (Blackmore, 2001; Bueno, 2017; Gerken, 2018). Dawkins define meme como una imagen, video o fragmento de texto de origen normalmente humorístico, que los usuarios de internet copian y difunden rápidamente, a menudo con ligeras variaciones (Blackmore, 2000).

Gerken (2018) reflexiona acerca de las características necesarias para que un meme pueda ser considerado como tal. Según el periodista británico una sola imagen no puede ser un meme. Tiene que ser copiada y difundida con variaciones de la imagen original. Gerken concluye que el primer meme grabado fue una caricatura publicada en 1921 por "Yesterday's Print", una página web que todavía comparte contenido histórico para resaltar las similitudes del pasado y el presente.

Es condición obligatoria que el meme tenga una característica vírica, es decir, de propagación. Las redes sociales están actualmente plagadas de este tipo de imágenes, pues los usuarios de internet empatizan más con expresiones o manifestaciones con las que se puede identificar parcialmente (Granovetter, 1983).

\section{OBJETIVOS}

En los institutos de secundaria y bachillerato no existe una hoja de ruta generalizada para el uso de los nuevos dispositivos electrónicos. Tal como figura en el Decreto 234/1997, de 2 de septiembre, DOGV núm. 3073, la normativa interna de cada centro es la que marca las pautas de acción. Utilizar el móvil como material de clase puede aportar muchas ventajas respecto a otros materiales; por ejemplo, el docente se asegura que el alumno lo llevará consigo, además es una herramienta que todos manejan con facilidad y prácticamente todo el alumnado tiene uno, de forma que no es necesario exigir un gasto adicional a las familias.

Los objetivos propuestos son los siguientes:

- Aprovechar las redes sociales por sus características como herramienta de uso en clase y realizar las tareas de forma grupal para promover el trabajo cooperativo.

Vivat Academia. Revista de Comunicación. 15 junio 2020 /15 septiembre 2020, nº 151, 25-45 
- Poder sustituir modelos de enseñanza convencionales por metodologías que incluyan elementos más atractivos para los alumnos en general y obtener resultados iguales o superiores de aprendizaje.

- Averiguar si la red social Instagram puede ser considerada como herramienta útil dentro de la clase de música u otras materias en niveles de educación secundaria.

\section{METODOLOGÍA}

Esta experiencia se ha llevado a cabo con 95 alumnos de la asignatura de música provenientes de dos grupos de $4^{\circ}$ de la $\mathrm{ESO}$, con un total de 60 alumnos, y un grupo de $1^{\circ}$ de Bachillerato de 35 estudiantes de un instituto público del área metropolitana de Valencia. Nos hemos servido de las TIC para que el alumnado pudiese utilizar la red social Instagram con fines pedagógicos. En concreto, los estudiantes tenían que crear sus propios memes. El profesorado diseñó una circular de consentimiento dirigida a los padres y madres del centro para que diesen su conformidad con el fin de que el alumnado crease su propia red social en Instagram.

La idea original de utilizar la red social Instagram ha surgido de la combinación de proporcionar a los alumnos una forma de trabajar motivadora y autónoma utilizando elementos poco convencionales y aprovechando los recursos de una forma práctica; aunque su propósito no sea pedagógico originalmente.

Una de las claves para que el alumnado aprenda de una forma significativa es la motivación. Así, por ejemplo, Naranjo (2009) asevera que en ambientes educativos es fundamental crear expectativas sobre el alumnado para que los estudiantes sean capaces de ejecutar la tarea asignada. Asimismo, la libertad de elección, de creación o de distribución de la tarea contribuye significativamente a fomentar la sensación de autonomía y a que los alumnos se vean más capaces de autorregularse (Alonso, 2005). En este sentido, los alumnos no presentaron ningún problema de manejo ni de la red social ni de la aplicación para crear memes, por lo que no ha sido necesario emplear tiempo en explicar su funcionamiento. Las dudas que han surgido en el día a día han sido de carácter metodológico o de contenido.

La actividad está basada en una metodología constructivista, en la que el conocimiento nuevo se construye en base a experiencias pasadas y los elementos clave de la producción del aprendizaje significativo son la participación activa de los alumnos y la sociabilización de los mismos (Cooperstein y Kocevar-Weidinger, 2004). A su vez, esta metodología se combina con el modelo "Flipped Clasroom". A los aspectos básicos de esta actividad, como son el trabajo cooperativo, la libertad de creación, la utilización de herramientas afines a los alumnos y el carácter integrador proporcionado por el modelo "Flipped Clasroom", hay que sumar la autoevaluación. En pro de fomentar este aspecto, se diseñó una encuesta pensada para que los estudiantes respondiesen conjuntamente al final de cada sesión. 


\subsection{Instrumentos de recogida de datos}

Encuesta diaria

Al final de cada sesión de trabajo en clase los alumnos participaban en una breve encuesta con cuestiones respectivas al trabajo en grupo que se citan a continuación:

- Establecer objetivos: principal y concretos.

- Respetar las opiniones de los demás.

- Trabajo eficiente: distribución de tareas.

- No atascarse en algo, pasar de largo y volver o no sobre ello.

- Compromiso tácito entre los miembros del grupo.

- Programar/planificar el tiempo de trabajo.

Con esta encuesta se pretendía medir el grado de satisfacción del grupo respecto a la productividad del trabajo realizado. La respuesta a cada apartado debía ser grupal, es decir, si no estaban todos satisfechos con algún apartado se dejaba constancia de ello, apuntando únicamente un resultado positivo total si nadie ponía objeciones.

Estos puntos se leyeron conjuntamente antes de iniciar la actividad, para que los alumnos tuvieran una guía y una idea de aquello que se les iba a requerir o se tenían que exigir ellos mismos. Durante el desarrollo de la actividad se leían al final de cada sesión de trabajo colaborativo y todos los asistentes a la clase respondían a cada apartado, punto por punto.

Diario de sesiones

El diario de sesiones es la recogida periódica de información del transcurso de las clases. Este elemento tiene la mayor utilidad cuando se trata de recordar cronológicamente la distribución de las sesiones, y algunos acontecimientos relevantes. Es un elemento clave en la recogida de información cuando esta depende en parte de la observación del maestro.

\section{Instagram}

La cuenta que los alumnos han creado y rellenado en Instagram es el resumen del contenido que han trabajado, además de ser el elemento principal de evaluación. La subida de imágenes se ha hecho siempre bajo la supervisión del docente, provocando a veces la eliminación de alguna imagen que ya estaba colgada en la red por motivos diversos, como son faltas de ortografía, falta de información en la descripción o ausencia de hástags.

Encuesta de satisfacción

El último elemento es la encuesta de satisfacción compuesta para obtener respuestas de opinión acerca del diseño de la actividad y su desarrollo en el aula. 
Sirve en parte para evaluar la actividad, pero también para analizar posibles cambios para futuras aplicaciones. Que la actividad sea de agrado de los alumnos y éstos se sientan motivados durante la realización es muy relevante a la hora de conseguir un aprendizaje de calidad.

\subsection{Diseño de la actividad}

La actividad consiste en la creación de una cuenta temática en la red social Instagram. Se realiza de modo cooperativo, de forma que el resultado final es la suma de todas las aportaciones. La cuenta debe contar con los siguientes elementos: nombre y foto de portada, una descripción del perfil y las imágenes con sus respectivas descripciones en el pie de foto incluyendo "hashtags". Las imágenes serán "memes" y cada una deberá tratar de un contenido distinto cumpliendo las características propias de este tipo de imágenes. La cuenta estará completa cuando posea todos estos elementos y haya al menos 10 imágenes creadas. La temporalización de la actividad ha sido de 5 sesiones en cada curso. Hay que tener en cuenta que en $4^{\circ}$ curso de la ESO y primero de bachillerato disponemos de tres sesiones semanales de música.

Se utiliza el trabajo grupal para que los alumnos practiquen las pautas básicas del mismo y para fomentar la sociabilización, lo cual favorece también la motivación. La eficacia se consigue mediante la planificación y la cooperación de todos los miembros. Trabajar en grupo "conlleva la necesidad de asumir la responsabilidad de contribuir activamente en la elaboración de una tarea grupal y de aprender a resolver las diferencias que surgen durante su desarrollo" (Navarro et al. 2013, p. 2).

En cuanto a la recogida de datos durante el desarrollo de la actividad se utiliza el método de la observación con su respectivo diario de sesiones (Sierra, 1997). Es importante que el docente, aunque no participe en los debates de los alumnos, observe su comportamiento; la manera de expresarse entre ellos y cómo evoluciona su criterio. En este sentido, Vygotsky (1978) advierte que el comportamiento de los alumnos bien observado define su forma de pensar y es un reflejo de sus conocimientos. Hay que tener en cuenta que en las metodologías de tipo constructivista es importante que el sujeto sea capaz, mediante la reflexión, de expresar unas ideas que son subjetivas (Karagiorgi y Symeou, 2005). Por esta razón el docente concede mayor importancia a las respuestas abiertas sin esperar una respuesta tipo.

Previamente a la realización de la primera sesión en la que se inicia la actividad se explica a todo el grupo lo que se va a hacer, describiendo los elementos que conforman la tarea y su funcionamiento general. Además se dan las instrucciones que servirán de referencia durante la aplicación de la misma.

En la primera sesión se realiza una exposición sobre los usos negativos de las redes sociales en adolescentes. En determinados centros de educación secundaria el móvil supone un elemento de distracción, incluso se llega a utilizar como 
herramienta de conductas inapropiadas en el instituto con el profesor o los compañeros. Por este motivo se considera imprescindible explicar a los alumnos cómo llevar a cabo un uso correcto del móvil y de las redes sociales, así como las consecuencias de una mala praxis de estas herramientas. En esta misma sesión se procede también a la creación de la cuenta en Instagram con el nombre de usuario y la contraseña.

En la sesión siguiente se asignan los contenidos temáticos que la cuenta deberá incluir al finalizar la actividad. El alumnado ha de visualizar unos vídeos explicativos del tema y resumirlos. Los estudiantes se deben distribuir la visualización de los distintos materiales; no obstante, el profesor supervisa que se haga de forma equitativa. Todo el contenido del tema debe estar incluido de forma distribuida en los resúmenes. Una vez todos los alumnos han realizado la tarea pertinentemente y se posee la información teórica necesaria se procede a la creación de un cronograma donde aparecerán los hechos más relevantes: fechas, acontecimientos y personajes transcendentes. La utilidad del cronograma es doble: por un lado constituye una herramienta de consulta que el alumnado podrá disponer en todo momento. Por otra parte, servirá para corroborar que todos los contenidos han sido incluidos en las distintas imágenes cuando la cuenta de Instagram haya finalizado.

En las sesiones siguientes se procede a la creación de imágenes (memes) con sus respectivas descripciones y hashtags. Este apartado de la actividad se realiza en clase, pues es importante llevarlo a cabo de forma cooperativa para aprovechar los beneficios de este formato de trabajo. Los tres grupos cumplieron con las delimitaciones temporales sin problema.

En la última sesión, con la cuenta finalizada y revisada se procede a realizar una visualización de videos directamente relacionados con la temática y el comentario de los mismos por parte del alumnado, respondiendo a preguntas cerradas y abiertas.

\subsection{Instrumentos de evaluación}

- Observación directa del profesor: la observación del docente, en cuanto a la evaluación de la actividad solo supone un elemento interventor en caso de que haya algún alumno que realiza un volumen de trabajo muy inferior al resto.

- La autoevaluación periódica es un instrumento de medición de la evolución a corto plazo en los aspectos básicos del trabajo cooperativo. Si la satisfacción de los alumnos ha ido en aumento se relaciona con un significado positivo en este sentido.

- Encuesta de satisfacción al alumnado participante que se realiza por internet: Es muy relevante la opinión sincera de los alumnos acerca de la actividad en general, para rediseñarla y comprobar si el esfuerzo que supone preparar y aplicar esta actividad es provechoso para el funcionamiento de la clase. 
- Prueba de evaluación escrita en la última sesión: Este instrumento sirve sobre todo, para medir el nivel de utilidad de la actividad de la realización de la cuenta de Instagram.

\section{RESULTADOS}

\subsection{Encuesta diaria}

La encuesta diaria constaba de seis cuestiones que el alumnado respondía al finalizar cada sesión. La condición para que se marcase un punto como logrado era que todos los miembros asistentes afirmaran que se había cumplido. Si no todos estaban seguros de que se hubiera logrado se indicaba como no logrado. La respuesta debía ser unánime. Para clarificar el significado de cada punto, previniendo de que la literalidad de las frases no fuera entendida por todos se hacían las aclaraciones necesarias las veces que hiciera falta.

Con un año de diferencia, los alumnos de bachillerato trabajaron de forma más eficiente en lo que respecta al trabajo grupal. No obstante en los tres grupos demostraron que con las directrices adecuadas aumentaban la eficacia del trabajo. Hubo más intervenciones del docente para asesorar a los dos grupos de $4^{\circ}$ de la ESO, pero la progresión en poco tiempo fue evidente en todos los grupos.

En los dos cursos de $4^{\circ}$ de la ESO se pudo apreciar una evolución más significativa, puesto que la primera sesión que realizaron resultó caótica en cuanto al trabajo en grupo. Ellos mismos se autoevaluaron honestamente negando la consecución de los seis puntos. La observación docente permite aclarar en cuales de las siguientes sesiones se requirió asistencia, tanto para contribuir a la adquisición de estos valores como para asegurarse de que la actividad seguía el cronograma previsto. Mientras tanto, los alumnos de primero de bachillerato mostraron una adaptación más rápida y eficaz.

\subsection{Resultados de la aplicación de nuevas metodologías}

El tema de trabajo escogido ha sido el musical, siguiendo la programación del curso de la profesora. Se trata de un tema de actualidad que puede resultar bastante prolífico en cuestión de creación de memes. A continuación, se muestran algunos ejemplos del resultado final de la cuenta de Instagram de $1^{\circ}$ de bachillerato: 
Blasco Magraner, J. S. y López Ramos, R.

Instagram como herramienta de aprendizaje musical en educación secundaria y bachillerato

(0) | Instagram

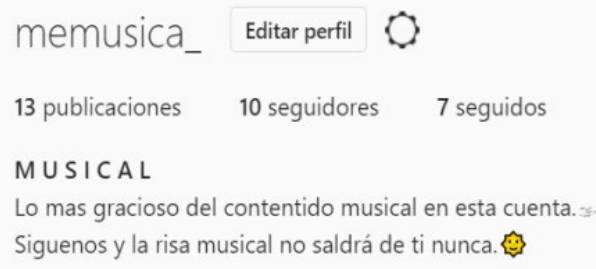

Imagen 1: portada del perfil de Instagram.

Fuente: elaboración propia, 2019.

En la imagen 1 tenemos la descripción de la cuenta, donde indica el nombre, la imagen de cabecera y cuál es el contenido de su perfil. En este caso, y siguiendo la programación del curso de la profesora, se ha escogido el musical, que es un tema de actualidad y puede resultar bastante prolífico en cuestión de creación de memes.
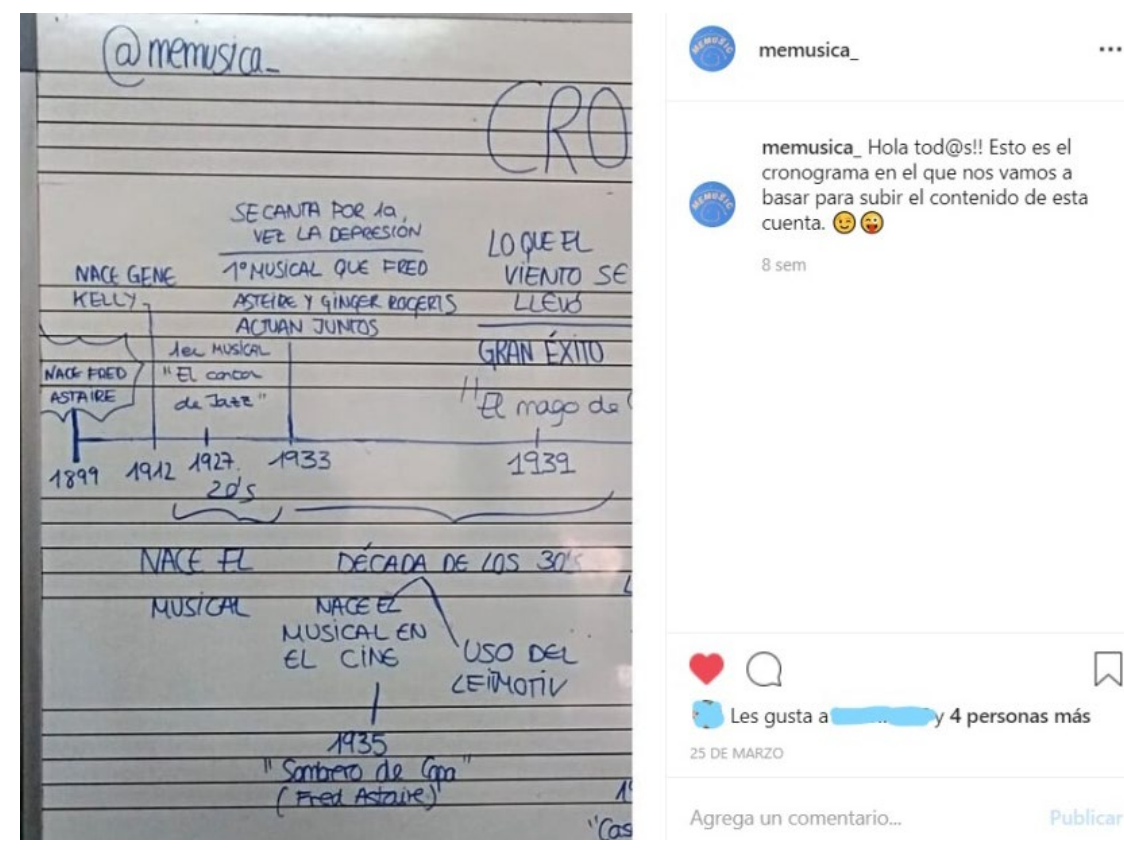

Imagen 2: imagen de un fragmento del cronograma en Instagram.

Fuente: elaboración propia, 2019.

En la imagen 2 aparece una parte del cronograma que los alumnos realizaron para esquematizar la información y tener una referencia de los contenidos que debían tener al finalizar el proceso. 


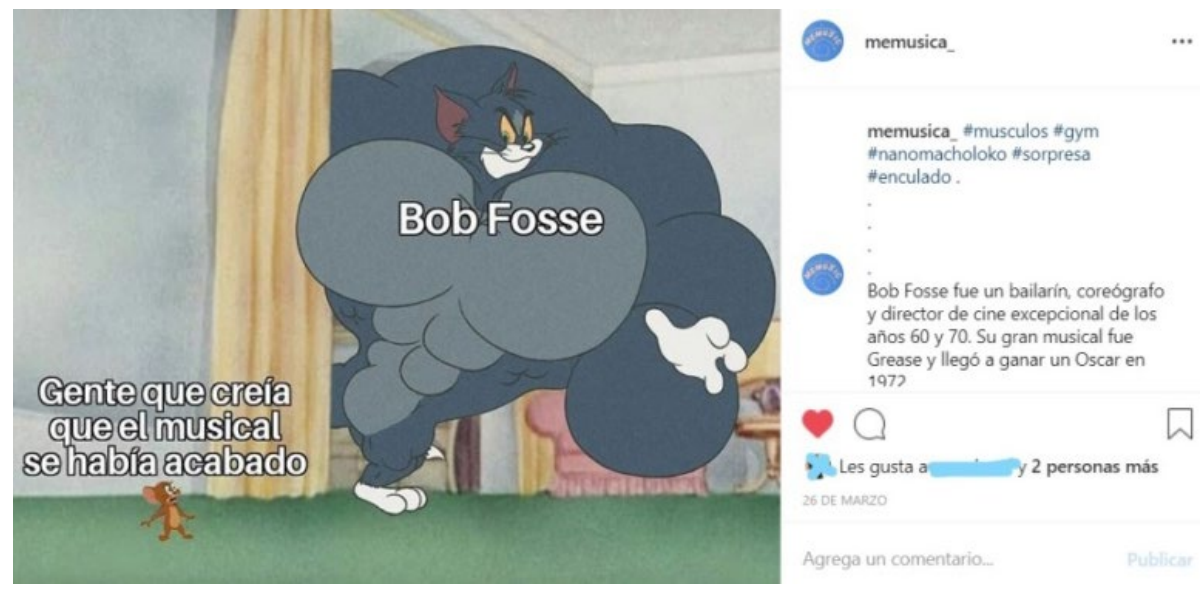

Imagen 3: el alumnado homenajea a Bob Fosse, figura de referencia del género musical cinematográfico.

Fuente: elaboración propia, 2019.

En la imagen 3 podemos apreciar un meme, representado con la imagen de "Tom y Jerry" en la que el gato sorprendería al ratón mostrando una fuerza inesperada. En la descripción de la foto aparece el significado de la imagen, relacionada con el actor, bailarín y director de cine Bob Fosse y su influencia en el cine de los años 60 y 70.

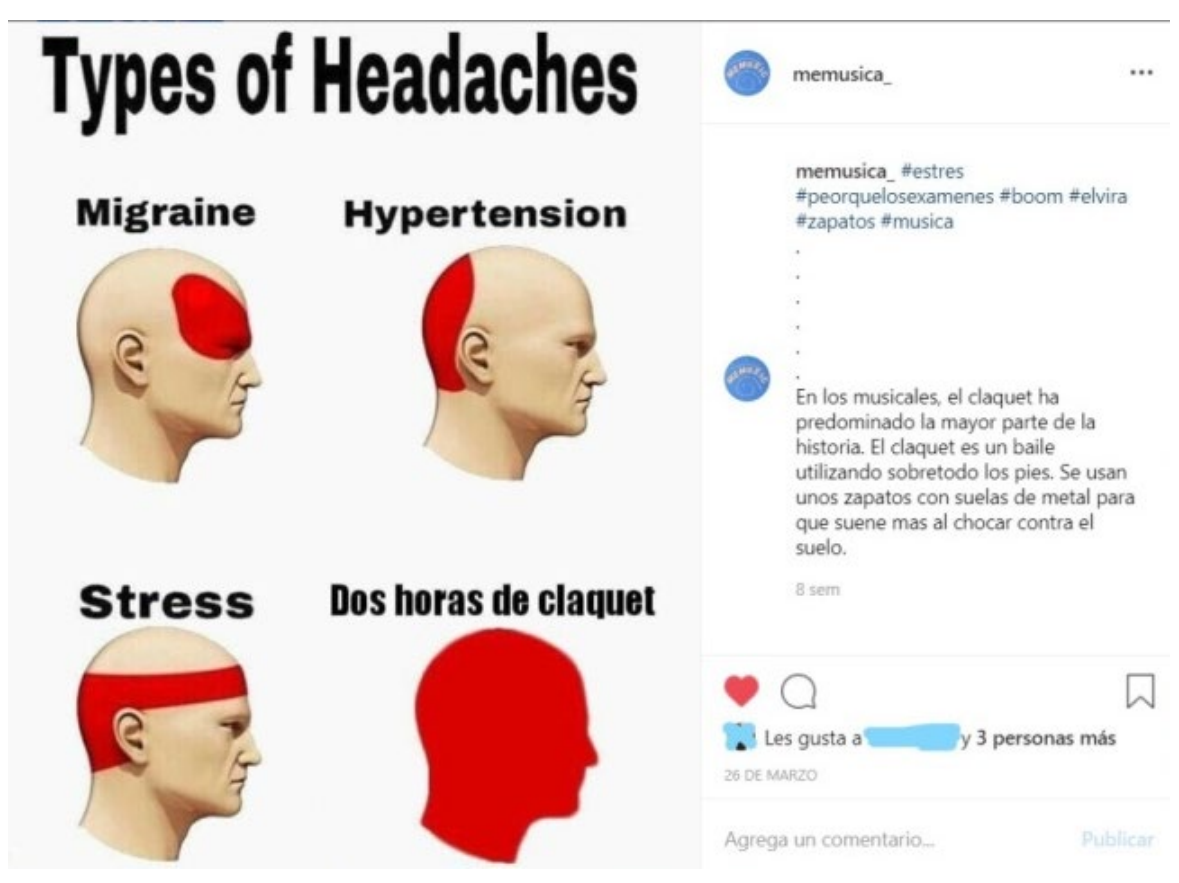

Imagen 4: el alumnado visualiza con ironía las tensiones producidas por la práctica del "claquet".

Fuente: elaboración propia, 2019.

En la imagen 4 encontramos una referencia humorística a la importancia que tenía el "claquet" en los musicales. El meme se utiliza para mostrar cosas que pueden llegar a resultar molestas, no estrictamente en el sentido físico. 


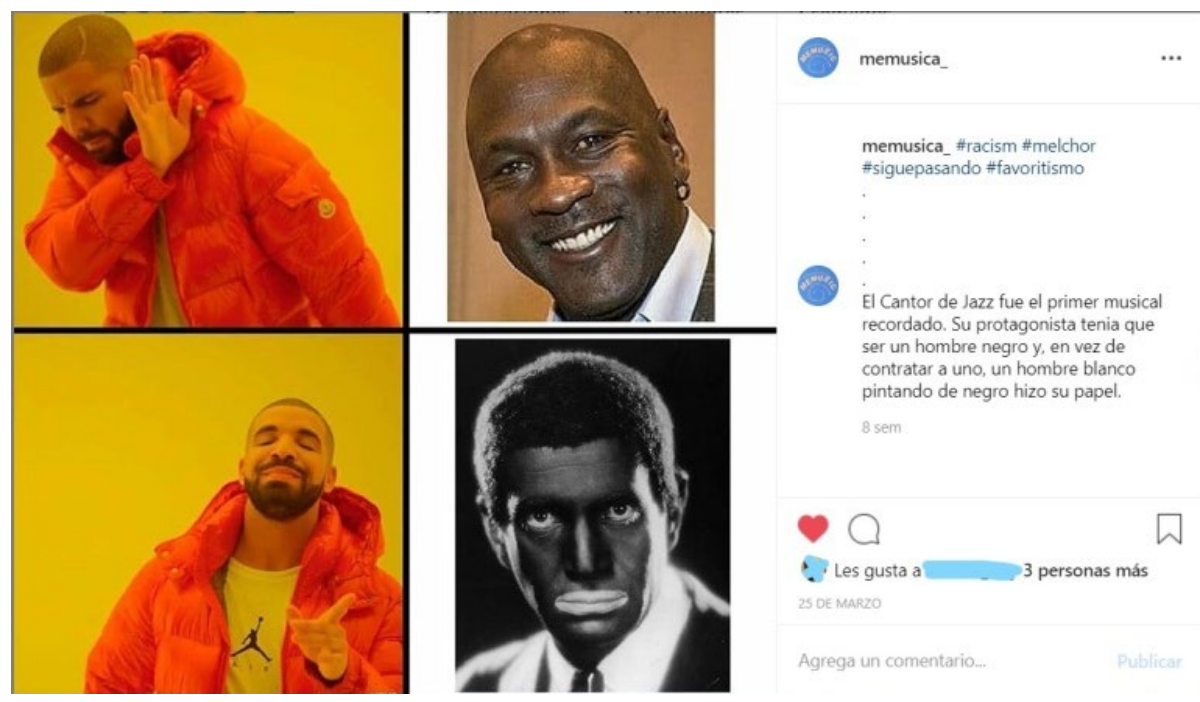

Imagen 5: el alumnado hace referencia al racismo.

Fuente: elaboración propia, 2019.

El meme de la Imagen 5 es muy utilizado. Su significado es simple: muestra una preferencia. En la foto de Instagram el alumnado ha querido hacer una mención al racismo que había en el siglo XX cuando ni siquiera se contrataba a un actor de color en un guion en el que el protagonista era un hombre de raza negra. El protagonista fue un hombre blanco caracterizado con rasgos de negro.

\subsection{Instagram y su utilidad en el aula de música y de análisis musical}

Para evaluar la actividad y puntuar numéricamente a los alumnos se consideró principalmente la cuenta de Instagram creada. Al inicio de la actividad se dieron una serie de instrucciones, entre las cuales estaban los contenidos que debía poseer el perfil en su forma final: una foto de portada, nombre, descripción de la cuenta y un número mínimo de imágenes en total, con sus respectivas descripciones y "hashtags", además de incluir entre las imágenes el cronograma en el que aparecían reflejados los contenidos del tema. Cuestiones como la ortografía también serían tenidas en cuenta.

El examen que se realizó para comprobar el nivel de conocimientos adquiridos no hacía media con la cuenta de Instagram, pero influyó para decidir la nota final. La puntuación se realiza sobre 2 puntos, ya que es el peso que la profesora da a la parte teórica en cada trimestre. En ambos cursos se plantearon las mismas condiciones. Las puntuaciones finales fueron:

- 1,5 sobre 2 para los dos grupos de $4^{\circ}$ de ESO, porque faltaban descripciones en algunas imágenes.

- 1,75 sobre 2 para el grupo de primero de Bachillerato, por la falta de expresión escrita, que pese a no ser un contenido de la asignatura de música, es considerado como un elemento transversal y necesario para averiguar el conocimiento de un alumno. 
El examen no se planteó como elemento constituyente de la evaluación grupal, sino como instrumento de medida para comprobar el nivel de contenidos que los alumnos poseen después de la realización de la actividad. Esta prueba está construida mediante la combinación de preguntas abiertas y cerradas, incluso en algunas de las cuestiones diversas respuestas bien argumentadas son válidas. El contenido trabajado en la clase de $4^{\circ}$ de ESO fue la música en los anuncios, y en el examen se reprodujeron 4 anuncios con características distintas para los cuales los alumnos tenían que rellenar el siguiente modelo de examen.

1- Tipo de música (original o prestada).

Los conceptos de música original y música prestada forman parte del contenido del tema de la música en los anuncios, y es un conocimiento básico que deben poseer al finalizar el tema. De esta forma, después de ver el anuncio debían señalar si se trataba de música original o prestada.

Respuestas correctas: 50; 83,3\%

Respuestas incorrectas: $10 ; 16,6 \%$

2- ¿En qué medida aparecen las funciones de la música en este anuncio?

Tabla 1. Funciones de la música en el anuncio.

\begin{tabular}{|l|l|l|l|l|l|}
\hline $\begin{array}{l}\text { Funciones de la } \\
\text { música }\end{array}$ & $\mathbf{1}$ & $\mathbf{2}$ & $\mathbf{3}$ & $\mathbf{4}$ & $\mathbf{5}$ \\
\hline $\begin{array}{l}\text { Reforzar el } \\
\text { contenido }\end{array}$ & & & & & \\
\hline $\begin{array}{l}\text { Ayudar a } \\
\text { memorizar el } \\
\text { mensaje y } \\
\text { producto }\end{array}$ & & & & & \\
\hline $\begin{array}{l}\text { Resaltar lo más } \\
\text { importante }\end{array}$ & & & & & \\
\hline $\begin{array}{l}\text { Captar la } \\
\text { atención del } \\
\text { oyente y } \\
\text { despertar } \\
\text { interés }\end{array}$ & & & & & \\
\hline
\end{tabular}

Fuente: elaboración propia, 2019.

Cada anuncio está diseñado de una forma, y la música no siempre juega el mismo papel. En esta pregunta no se pretende que los alumnos hayan memorizado las distintas funciones, si no que demuestren que hayan entendido en qué consisten las diversas funciones y sean capaces de analizar una información mentalmente 
mediante la escucha. Esta pregunta no está sujeta a una respuesta cerrada; es subjetiva dentro de unos límites de adecuación y coherencia.

3- ¿Está relacionada la música con el producto y/o con los consumidores?

La relación de la música con el producto, con el objetivo de conseguir que el consumidor se identifique con el mismo o lo recuerde es bastante frecuente. Cabe decir que en esta pregunta se han obtenido respuestas pobres por parte del alumnado, tal vez por la propia formulación de la cuestión.

4- ¿La música estructura el anuncio? ¿Por qué?

De nuevo en esta pregunta los alumnos muestran una capacidad limitada para expresar sus opiniones mediante la expresión escrita, lo cual provoca la duda en el docente de si no saben expresarse de forma redactada o si la cuestión es que no tienen una opinión lo suficientemente fundamentada como para expresarla. Este factor ha penalizado en ambos grupos.

¿Crees que es un buen anuncio? Redacta tu respuesta.

La parte positiva de esta pregunta es que se han obtenido respuestas muy diversas, lo cual muestra una implicación, al menos, suficiente en la tarea que se está realizando a la par que un conocimiento mínimo del tema. Siguiendo la recomendación de la tutora de prácticas, se especifica en el enunciado de las preguntas y posteriormente de forma oral que los alumnos tienen que explayarse un mínimo en sus respuestas.

Por su parte, en primero de bachillerato el contenido incluía las cuestiones más relevantes del musical y su historia. En el examen se reprodujeron cuatro videos de escenas representativas de diferentes musicales, para el que era necesario tener unos conocimientos mínimos de los musicales:

1- Indica los siguientes datos de cada musical:

- Etapa en la que se encuadra.

Para responder a esta cuestión es necesario saber el año exacto o aproximado de estreno, es decir es un conocimiento teórico de memorización que no implica reflexión. Las respuestas erróneas a esta primera pregunta son anecdóticas.

- Público al que va dirigido mayormente.

En esta pregunta caben distintas respuestas, ya que los alumnos no han tratado en los contenidos ningún apartado que responda a esta cuestión, más bien se trata de una reflexión que deben hacer basándose en la temática de cada musical, la tipología 
de la música y las letras de las canciones. Salvo una respuesta ambigua, las demás son coherentes aunque difieran mínimamente.

2- Describe de forma redactada los elementos característicos, intencionalidad y tu opinión personal de este musical.

En esta última pregunta se busca que los alumnos muestren su capacidad crítica, además de demostrar que son capaces de distinguir los elementos realmente importantes y que definen cada musical. Los alumnos han mostrado tener un conocimiento general del tema y específico de los musicales en la mayoría de casos.

\subsection{Resultados de la encuesta de satisfacción}

En la encuesta realizada hay una serie de preguntas que están redactadas en términos motivacionales. La opción de respuesta para los alumnos está ordenada numéricamente, siendo 1 la menor y 5 el máximo. Es resaltable señalar que ningún alumno ha respondido por debajo del 3, que sería el valor neutro, lo cual indica que la actividad ha sido valorada positivamente y en general se han sentido motivados durante su realización.

Tabla 2. Esta actividad ha despertado mi interés para aprender música/análisis musical.

\begin{tabular}{lll}
\hline Categoría & $\mathrm{N}$ & Porcentaje \% \\
\hline 1 No & 0 & 0 \\
2 Muy poco & 0 & 0 \\
3 Un poco & 28 & 29,47 \\
4 Bastante & 38 & 40,1 \\
5 Mucho & 29 & 30,52 \\
\hline
\end{tabular}

Fuente: elaboración propia, 2019.

Tabla 3. Me he sentido motivado mientras realizábamos la actividad de creación de "memes" en música/análisis musical en Instagram.

\begin{tabular}{lll}
\hline Categoría & N & Porcentaje \% \\
\hline 1 No & 0 & 0 \\
2 Muy poco & 0 & 0 \\
3 Un poco & 21 & 22,10 \\
4 Bastante & 33 & 34,73 \\
5 Mucho & 41 & 43,15 \\
\hline
\end{tabular}

Fuente: elaboración propia, 2019. 
Al ser preguntados directamente por la motivación, un porcentaje alto del alumnado responde positivamente a esta cuestión. Los valores del 4 y el 5 alcanzan el $77,88 \%$ de las respuestas, mientras que sólo el 22,10\% han seleccionado el valor 3.

Tabla 4. Prefiero esta metodología a las actividades convencionales.

\begin{tabular}{lll}
\hline Categoría & $\mathrm{N}$ & Porcentaje \\
\hline Sí & 83 & 87,3 \\
No & 0 & 0 \\
Indiferente & 12 & 12,63 \\
\hline
\end{tabular}

Fuente: elaboración propia, 2019.

Tabla 5. ¿Te gustaría volver a hacer la actividad de creación de "memes" en música/análisis musical?

\begin{tabular}{lll}
\hline Categoría & $\mathrm{N}$ & Porcentaje \\
\hline Sí & 77 & 81,05 \\
No & 0 & 0 \\
Indiferente & 18 & 18,94 \\
\hline
\end{tabular}

Fuente: elaboración propia, 2019.

El 81,05\% considera que le gustaría volver a realizar esta actividad; hecho que indica que los alumnos tienen una visión positiva de esta metodología después de haber realizado la actividad al completo.

\subsection{Diario de sesiones}

Se han cumplido las expectativas que el docente se había programado al principio de la actividad, si bien, tras la realización de la misma, se recomienda variar la temporización en los grupos de $4^{\circ}$ curso de la ESO para que estos dispongan de, al menos, una sesión más que los de bachillerato. Este hecho se debe a que su tiempo de adaptación y las dificultades que encuentran para llevar a cabo la actividad es mayor. No obstante, los objetivos se han visto cumplidos y el grado de consecución de los mismos por parte del docente y del alumnado, ha resultado satisfactorio.

\section{CONCLUSIONES}

Desde hace varias décadas se señala la importancia de renovar las metodologías docentes en los centros educativos a través de las TIC, favoreciendo, a su vez, el trabajo colaborativo en el alumnado (Ovejero, 1990). La innovación docente pasa en muchos casos por la utilización de las TIC que proporcionan una gama muy amplia de herramientas. Además, las TIC pueden convertirse en instrumentos poderosos para promover el aprendizaje, tanto desde un punto de vista cuantitativo como cualitativo (Carneiro, 2011). En la clase de música y análisis musical las TIC nos han ayudado en la búsqueda y selección de información de los contenidos y las imágenes 
con los que se han diseñado los memes. El alumnado se ha servido de internet para ampliar información sobre el género musical, tema que estaban estudiando en el libro de texto. Después, han tratado de enseñar mediante la creación de memes algunas temáticas propias de este género, como el racismo, la tensión de los artistas y figuras destacadas de este estilo. Todo ello ha contribuido a afianzar los conocimientos que el alumnado poseía sobre este estilo musical. En este sentido, los buenos resultados obtenidos en los exámenes de los tres grupos muestran el cumplimiento de los objetivos de la investigación.

La actividad de crear memes utilizando la red social Instagram ha sido altamente productiva y satisfactoria, tanto en los dos grupos de $4^{\circ}$ de la ESO como en el de primero de bachillerato Los resultados positivos que se han obtenido confirman la validez de Instagram como herramienta útil con fines didácticos. Se trata de una red social en la que el alumnado se siente familiarizado y, por esta razón, los estudiantes se muestran motivados en el desempeño de la tarea asignada.

La creación de la cuenta de Instagram no planteó problemas a nivel de manejo y conocimiento de la aplicación. Es cierto que en el grupo de primero de bachillerato el resultado fue más completo a nivel de contenido. Cada publicación poseía una descripción que acompañaba unas imágenes todas con gran sentido. Los grupos de $4^{\mathrm{O}}$ de la ESO también cumplieron con los mínimos requeridos, pero necesitaron un asesoramiento mayor. Por todo ello se sugiere que la aplicación de esta misma actividad en cursos todavía inferiores a $4^{\circ}$ de la ESO pueda demandar un planteamiento distinto, con un asesoramiento más planificado previamente de su aplicación.

La creación de los memes ha dado como resultado una muestra de imaginación y creatividad más que aceptable en los tres grupos. Los propios alumnos han sido quienes han escogido las imágenes y las han editado con el contenido apropiado. Este hecho ha propiciado de forma más natural la memorización del contenido. Hay que tener en cuenta que con la mínima expresión, la imagen del meme puede poseer un significado amplio. Por tanto, en una sola imagen los estudiantes han sido capaces de reflejar información cuantiosa y al mismo tiempo retener el significado.

Las encuestas diarias han reflejado la buena actitud de los tres grupos en todas las sesiones. Asimismo, las respuestas que se han obtenido de la encuesta de satisfacción indican que la visión del alumnado hacia la actividad ha sido muy buena. En definitiva, aplicaciones populares entre los jóvenes y adolescentes, en principio, no pensadas ni diseñadas para educar o ser utilizadas en un aula, pueden convertirse en herramientas aplicables en clase. Las características que poseen estas aplicaciones y, sobretodo, el apego, conocimiento y manejo que el alumnado tiene de ellas, colaboran a confundir positivamente a los estudiantes; puesto que estos incorporan elementos que utilizan para el ocio y el tiempo libre en el ambiente académico. Además, esta metodología aporta nociones de cómo trabajar eficientemente en equipo, hecho éste de suma utilidad en las distintas opciones que los alumnos vayan a seguir en su futuro académico y profesional. 
Blasco Magraner, J. S. y López Ramos, R.

Instagram como herramienta de aprendizaje musical en educación secundaria y bachillerato

\section{REFERENCIAS}

Alonso, R. P. (2017). Evaluación del fenómeno del Sexting y de los Riesgos emergentes de la Red en adolescentes de la Provincia de Ourense (Tesis inédita de doctorado). Vigo: Universidad de Vigo.

Blanco Martínez, A. (2017). Escribimos teatro a través de Instagram. Textos de didáctica de la lengua y la literatura, (77), 57-61.

Blanco Martínez, A. y López Fernández, R. (2017). La posibilidad pedagógica de la red social Instagram para aproximar a los estudiantes al género poético. En RuizPalmero, J., Sánchez-Rodríguez, J. y Sánchez. Rivas, E. (Edit.), Innovación docente y uso de las TIC en educación. Málaga: UMA Editorial.

Blackmore, S. (2001). Evolution and memes: the human brain as a selective imitation device. Cybernetics and Systems, an International Journal, (32), 225-255, doi: https://doi.org/10.1080/019697201300001867.

Bueno, C. (2017). El origen de los 'memes': historia del humor en Internet]. Eleconomista.es. Recuperado de https://www.eleconomista.es/tecnologia/noticias/8156168/02/17/

Campos, F. (2008). Las redes sociales trastocan los modelos de los medios de comunicación tradicionales, Revista Latina de Comunicación Social, (63), 45-68. doi: https:/ / doi.org/10.4185/RLCS-63-2008-767-287-29

Carneiro, R., Toscano, J. C. y Díaz, T. (2011). Los desafíos de las TIC para el cambio educativo. Madrid: Santillana.

Cooperstein, S. E., \& Kocevar-Weidinger, E. (2004). Beyond active learning: a constructive approach to learning. Emerald group publishing limited, 32(2), 141-148. doi: https:// doi.org/10.1108/00907320410537658.

Ditrendia, digital marketing trends (2018). Informe ditrendia: Mobile en España y en el Mundo. Recuperado de https://mktefa.ditrendia.es/hubfs/DitrendiaInforme\%20Mobile\%202018.pdf

Decreto 234/1997, de 2 de septiembre, del Gobierno Valenciano, por el que se aprueba el Reglamento orgánico y funcional de los institutos de educación secundaria. DOGV - Núm. 3073, de 8 de septiembre de 1997.

Educación 3.0 (2018). Educación 3.0. 13 redes sociales educativas: ¿cuál utilizas? Recuperado de https://www.educaciontrespuntocero.com/recursos.html 
Blasco Magraner, J. S. y López Ramos, R.

Instagram como herramienta de aprendizaje musical en educación secundaria y bachillerato

Educaweb (2018). Educaweb. Redes sociales: ventajas y desventajas para la formación. Recuperado de https://www.educaweb.com/noticia/redes-sociales-formacion$\underline{16408 /}$

Gabarda, S., Orellana, N. y Pérez, A. (2017). La comunicación adolescente en el mundo virtual: 1a experiencia de investigación educativa. Revista de Investigación Educativa, 35(1), 251-267. doi: https://doi.org/10.6018/rie.35.1.251171

Gerken, T. (2018). Is this 1921 cartoon the first ever meme? [BBC UGC \& Social News]. Recuperado de https://www.bbc.com/news/blogs-trending-43783521

González, M. A., Fernández, M. V., Urturi, A. F., Bregón, B. H., Moreno, M. M., y Molinero, L. R. (2015). Uso y riesgos de las tecnologías de la información y comunicación en adolescentes de 13-18 años. Acta Pediátrica Española, 73(6), 146.

Granovetter, M. (1983). The Strength of Weak Ties: A Network Theory Revisited. Sociological Theory, (1), 201-233. doi: https://doi.org/10.2307/202051

Jurado S. B., Woelfert E., Giovagnola A. C., Faisal F. B. y Peralta R. V. (2018). La incorporación de la red social Instagram con fines didácticos en el Curso de Microscopía Electrónica de la FCV-UNLP. I Jornadas de Inclusión de Tecnologías Digitales en la Educación Veterinaria. La Plata, Argentina: Universidad Nacional de La Plata.

Kamel Boulos, M. N., Giustini, D. M. \& Wheeler, S. (2016). Instagram and WhatsApp in health and healthcare: an overview. Future Internet, 8(3), 37-50. doi: https://doi.org/10.3390/fi8030037

Karagiorgi, Y. \& Symeou, L. (2005). Translating Constructivism into Instructional Design: Potential and Limitations. Educational Technology \& Society, 8(1), 17-27.

Kwak, H., Lee, C., Park, H. \& Moon, S. (2010). What is Twitter, a social network or a news media? ACM New York. doi: https://doi.org/10.1145/1772690.1772751

Moreno, M. P. (2018). Uso docente de la red social Instagram en la asignatura de Proyectos 1, Jornadas sobre Innovación Docente en Arquitectura. Zaragoza. doi: https://doi.org/10.5821/jida.2018.5511

Naranjo Pereira, M. L. (2009). Motivación: perspectivas teóricas y algunas consideraciones de su importancia en el ámbito educativo. Revista Educación, 33(2), 153-170.

Navarro, J. P., Sala, H., Limbiati, V., Corda, F. y Moreno, D., (2013). Uso intensivo de herramientas de colaboración en línea en educación superior. Revista Electrónica de Didáctica en Educación Superior, (6). Recuperado de http://ojs.cbc.uba.ar/index.php/redes/article/view/85 
Oberst, U., Wegmann, E., Stodt, B., Brand, M. \& Chamarro, A. (2017). Negative consequences from heavy social networking in adolescents: The mediating role of fear of missing out. Journal of Adolescence, (55), 51-60. doi: https://doi.org/10.1016/j.adolescencia.2016.12.008

Ovejero, A. (1990). Aprendizaje cooperativo: Una alternativa eficaz a la enseñanza tradicional. Barcelona: Promociones y Publicaciones Universitarias.

Sherman, E. L., Payton, A. A., Hernández, M. L., Greenfield, M. P, \& Dapretto, M., (2016) The Power of the Like in Adolescence: Effects of Peer Influence on Neural and Behavioral Responses to Social Media. Sychological Science, 1-9. doi: https://doi.org/10.1177/0956797616645673

Sierra, R. B. (1997). Técnicas de investigación Social. Madrid: Editorial Paraninfo S. A.

Statista (2019). Distribution of Instagram users worldwide as of April 2019, by age group. Recuperado de https://www.statista.com/statistics/325587/instagram-globalage-group/

Vygotsky, L. S. (1978). Mind in Society. Cambridge: Harvard University Press.

\section{AUTORES:}

\section{José Salvador Blasco Magraner}

José Salvador Blasco Magraner es Doctor en Ciencias Sociales y Humanas y licenciado en Historia y Ciencias de la Música por la Universidad Católica de Valencia con nota media de sobresaliente. Recibió el Premio Extraordinario de Doctorado por su tesis titulada "Vicente Peydró Díez: vida y obra". Es también licenciado en Dirección de orquesta por la prestigiosa Associated Board of the Royal Schools of Music de Londres y diplomado en Didáctica de la lengua inglesa por la Universitat de València. En 1997 obtiene por oposición plaza en el cuerpo de maestros de música de enseñanza primaria en Barcelona (actualmente en excedencia). Asimismo, es editor de la editorial "Latina" en la colección de Cuadernos de Bellas Artes. Está acreditado por la Aneca en la figura de "Contratado Doctor". Es profesor Ayudante Doctor de la Universitat de València, en el departamento de Didáctica de la Expresión Musical, Plástica y Corporal.

j.salvador.blasco@uv.es

Orcid ID: https:// orcid.org/0000-0001-8937-5842

\section{Rubén López Ramos}

Título superior en el Conservatorio Superior de Música "Salvador Seguí" de Castellón, especialidad: interpretación de trombón. Máster universitario en Didáctica de la Música por la Universitat Jaume I de Castellón y Máster universitario en Profesor de Secundaria por la Universitat de València. Actualmente es profesor en la escuela de música Unió Musical de l’Eliana.

ruloramos@uv.alumni.es 